\title{
Association of HER-2 Expression with Age, Tumour Size, Grade, Differentiation and Lymph Node Deposit in Patients with Breast Cancer
}

\author{
Sharmin Ferdousi, ${ }^{1}$ Shah Md. Badruddoza, ${ }^{2}$ S M Asafuddullah ${ }^{3}$
}

\begin{abstract}
Breast Cancer incidence is increasing, but its mortality has started to decrease. The existence of strong reliable prognostic and predictive factors is of utmost importance to the practicing clinician. Some factors are only prognostic such as age, tumor size, and lymph node status, while others are both prognostic and predictive such as hormone receptors and human epidermal receptor 2 (HER's-2) status. This study was done to see the association of HER-2 positivity with age, tumour size, grade, differentiation and lymph node deposit in breast cancer patient. A cross-sectional type of descriptive study was conducted among 50 patients. Patient age range is from 22 to 64 years (mean $42.64 \pm 10.26$ years). Tumour size ranged from 1 to $8 \mathrm{~cm}$ (mean $4.39 \pm 1.564 \mathrm{~cm}$ ). Well differentiated tumour was 20 , moderately differentiated tumour was 18 cases and poorly differentiated was 12 cases. HER-2/neu negative included 35(70\%) cases and positive included $15(30 \%)$ cases. In this study it was found that the association between age groups and tumour differentiation with HER-2/neu status was statistically significant $(p=$ $<0.05)$.
\end{abstract}

Key words: Breast Cancer, HER-2/neu expression.

TAJ 2019; 32: No-2: 14-21

\section{Introduction}

Breast Cancer incidence is increasing, but its mortality has started to decrease. This reduction is a result of widespread screening resulting in earlier detection as well as advances in adjuvant treatment of early-stage disease. ${ }^{1}$ It is very important to be able to select the best available therapy for an individual patient based on established predictive factors.

Therefore, the existence of strong reliable prognostic and predictive factors is of utmost importance to the practicing clinician. Prognostic factors are different from predictive factors. A prognostic factor is any measurement that correlates with disease free survival or overall survival in the absence of adjuvant therapy and that also correlates with the natural history of untreated breast cancer. A predictive factor is any measurement that correlates with the response to a given therapy. Some factors are only prognostic such as age, tumor size, and lymph node status, while others are both prognostic and predictive such as hormone receptors and human epidermal receptor 2 (HER-2) status.

Oestrogen receptor (ER) and progesterone receptor (PR) status has been used for many years to help determine a patient's suitability for endocrine therapy. More recently, testing for the human epidermal growth factor receptor 2 (HER-2 / neu) has been included in routine patient work-

\footnotetext{
${ }^{1}$ Assistant Professor, Department of Pathology, Rajshahi Medical College, Rajshahi. 2 Professor \& Head, Department of Pathology, Rajshahi Medical College, Rajshahi.

3 Professor, Department of Pathology, Rajshahi Medical College, Rajshahi.
} 
up, with recognition of its value both as a prognostic marker and, more particularly, in predicting response to trastuzumab (Herceptin TM). HER2/neu protein has garnered a great deal of interest amongst pathologists and oncologists for its potential role as a tumor marker and prognostic marker.

\section{Materials and Methods}

This study was cross-sectional type of descriptive study was conducted among

50 patients admitted in the department of Surgery, Rajshahi Medical College Hospital and diagnosed histopathologically as breast cancer from January 2010 to December 2011.

\section{Inclusion criteria:}

- Females of any age diagnosed clinically and by FNAC as having breast cancer.

\section{Exclusion criteria:}

- Patients already treated or undergone biopsy followed by chemo/radiotherapy and male patients of invasive breast cancer.

\section{Ethical clearance:}

Prior to the commencement of this study, the research protocol was approved by the Institutional Review Board (IRB) of Rajshahi Medical College, Rajshahi.

\section{Clinical information:}

All the clinical information about the patients under study was noted on structured proforma.

\section{Sample collection:}

Mastectomy specimen/lumpectomy specimens were received in the laboratory. Routine tissue processing was followed. Paraffin blocks were made and sections were taken for routine Haematoxylene and Eosin (H\&E) stain and
Immunohistochemistry (IHC) stain. For IHC stain, sections were taken on sialinized slides

\section{Examination of tissue sections:}

Routinely stained sections were examined under microscope and histological diagnosis was made. All cases were classified according to WHO proposed classification (WHO 2003). In cases of invasive ductal carcinoma (NOS), grading of tumour was performed by the Bloom-Richardson grading system (Rosai 2004).

Immunohistochemistry (IHC) for HER-2/neu.

During this study, HER-2/neu reactivity were detected through immunohistochemical stain.

\section{Assessment of IHC staining for HER-2/neu protein}

HER-2/neu (c-erbB-2) over expression was measured by immunohistochemistry. Positive $\left(3^{+}\right)$ IHC staining was defined when more than $10 \%$ of tumour cells show strong complete membrane staining. Weakly positive (2+) IHC staining was defined when more than $10 \%$ of tumour cells show weak to moderate complete membrane staining. Negative IHC was defined when no staining was observed, or membrane staining was $<10 \%$ of the tumour cells. A faint/barely perceptible membrane staining when detected in $>10 \%$ of the tumour cells are also categorized as negative. In this study, score 2+ was interpreted as negative in the final statistical analysis as fluorescence in situ hybridization (FISH) was not performed on the weak positive cases $(2+)$.

\section{Analysis of data and results:}

After collection of data, descriptive statistics like percentage was calculated. Analysis of data was done with the help of computer by SPSS programme.

\section{Results}

Prognosis and management of breast cancer patient are influenced by some variable such as histological type, tumour differentiation (grade), tumour size, lymph node status and HER-2/neu expression pattern. A total 50 cases of invasive breast cancer were included in this study. 
Table 1: Distribution of patients according to age $(n=50)$

\begin{tabular}{ccc}
\hline Age in years & Number of cases & Percentage (\%) \\
\hline $21-30$ & 6 & $12 \%$ \\
$31-40$ & 18 & $36 \%$ \\
$41-50$ & 17 & $34 \%$ \\
$51-60$ & 7 & $14 \%$ \\
$61+$ & 2 & $4 \%$ \\
Total & 50 & $100 \%$ \\
\hline
\end{tabular}

Mean \pm SD $=42.64 \pm 10.26$ years.

Table 2: Distribution of tumour size $(n=50)$

\begin{tabular}{ccc}
\hline Tumour sizes & Number & $\%$ \\
\hline$<2 \mathrm{~cm}$ & 6 & $12 \%$ \\
$2-5 \mathrm{~cm}$ & 30 & $60 \%$ \\
$>5 \mathrm{~cm}$ & 14 & $28 \%$ \\
\hline
\end{tabular}

Mean \pm SD of size $4.39 \pm 1.564 \mathrm{~cm}$.

Tumour size ranged from 1 to $8 \mathrm{~cm}$ with a mean \pm SD of size $4.39 \pm 1.564 \mathrm{~cm}$. The median size was 4.45 $\mathrm{cm}$

Tumour differentiation (Grade) $(\mathrm{n}=50)$.

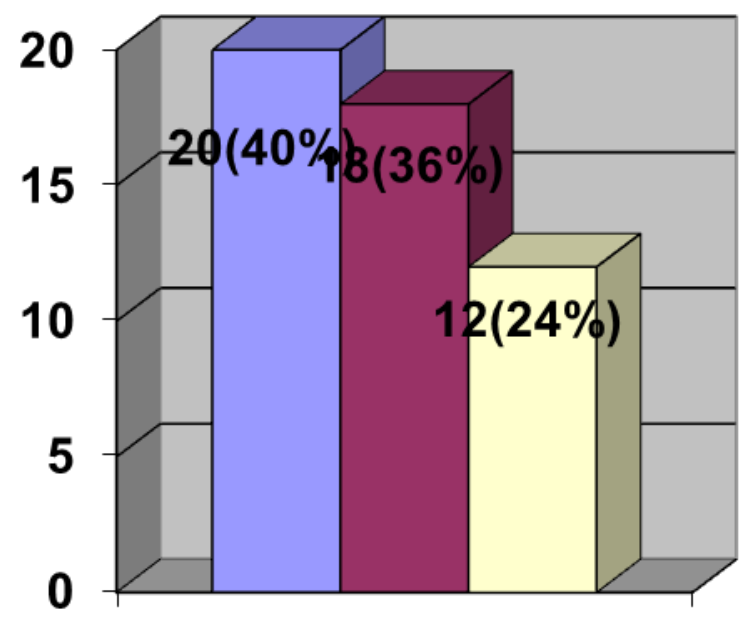

\begin{tabular}{|l|}
\hline$\square$ Well \\
differentiated \\
$\square$ Moderately \\
differentiated \\
$\square$ Poorly \\
differentiated \\
\hline
\end{tabular}

Figure 1: Frequency of Tumour differentiation $(n=50)$

Figure 1 showed the frequency of tumour differentiation. According to Bloom Richardson Grading system, carcinoma was graded into Grade I (well differentiated), Grade II (moderately differentiated) and Grade III (poorly differentiated). Well differentiated tumour was 20(40\%), moderately differentiated tumour was $18(36 \%)$ cases and poorly differentiated was $12(24 \%)$ cases. 


\section{Distribution of lymph node metastasis status $(n=50)$}

Lymph node status was divided into five groups. These were no lymph node metastasis, metastasis within 1-3 lymph nodes, metastasis within 4-9 lymph nodes, metastasis involving $\geq 10$ lymph nodes and lymph node status could not be assessed. Lymph node metastasis ranged from 0 to 13. Mean \pm SD of lymph node metastasis was 3.58 \pm .49. No lymph node metastasis was found in 7(14\%) cases, metastasis within 1-3 lymph node was found in 14(28\%) cases, metastasis within 4-9 lymph nodes was found in 17(34\%) cases, metastasis to $\geq 10$ lymph nodes was found in $4(8 \%)$ cases and lymph node status could not be assessed in $8(16 \%)$ cases.

Table 3: HER-2/neu reactivity patterns $(n=50)$

\begin{tabular}{ccc}
\hline HER-2 positivity & Number & $\%$ \\
\hline HER-2 negative & 35 & $70 \%$ \\
HER-2 positive & 15 & $30 \%$ \\
Total & 50 & $100 \%$ \\
\hline
\end{tabular}

Table 3 showed HER-2/neu reactivity patterns. HER-2/neu reactivity pattern was determined as negative $($ score $=0,1+)$, weakly positive $($ score $=2+)$ and positive $($ score $=3+$ ). Weakly positive $($ score $=2+$ ) was considered as negative due to unavailability of FISH technique. 27(54\%) cases were HER-2/neu negative (score $=0,1+$ ), 8(16\%) cases were weakly positive (score $2+$ ) and $15(30 \%)$ cases were positive (score $=3+)$. So negative $(0,1+, 2+)$ included $35(70 \%)$ cases and positive included $15(30 \%)$ cases.

Table 4: Relationship between HER-2/neu expression and age of the patients $(n=50)$

\begin{tabular}{cccccc}
\hline \multirow{2}{*}{ Age of the patients } & \multicolumn{2}{c}{ HER-2/neu+ve } & \multicolumn{2}{c}{ HER-2/neu-ve } & \multirow{2}{*}{ Total (\%) } \\
& $\mathrm{N}$ & $\%$ & $\mathrm{n}$ & $\%$ & \\
\hline$\leq 45$ years & 11 & $42.31 \%$ & 15 & $57.69 \%$ & $26(52 \%)$ \\
$>45$ years & 4 & $16.67 \%$ & 20 & $83.33 \%$ & $24(48 \%)$ \\
Total & 15 & $30 \%$ & 35 & $70 \%$ & $50(100 \%)$ \\
\hline
\end{tabular}

$$
\chi^{2}=3.907, d f=1, p=<0.05
$$

The table no 4 showed that among the patients of age group $\leq 45$ years, 11(42.31\%) cases were HER-2 positive and 15 (57.69\%) cases were HER-2 negative. Among the patients of age group $>45$ years, 4(16.67\%) cases were HER-2 positive and 20(83.33\%) cases were HER-2 negative. From this table it was found that the association between age groups and HER-2/neu status was statistically significant ( $p=$ $<0.05)$. 
Table 5: Relationship between HER-2/neu expression and tumour differentiation (n=50).

\begin{tabular}{cccccc}
\hline Tumour differentiation & \multicolumn{2}{c}{ HER-2/neu+ve } & \multicolumn{2}{c}{ HER-2/neu-ve } & Total (\%) \\
& $\mathrm{n}$ & $\%$ & $\mathrm{~N}$ & $\%$ & \\
\hline Well differentiated & 3 & $15.00 \%$ & 17 & $85.00 \%$ & $20(40 \%)$ \\
Moderately differentiated & 5 & $27.78 \%$ & 13 & $72.22 \%$ & $18(36 \%)$ \\
Poorly differentiated & 7 & $58.33 \%$ & 5 & $41.67 \%$ & $12(24 \%)$ \\
Total & 15 & $30 \%$ & 35 & $70 \%$ & $50(100 \%)$ \\
\hline
\end{tabular}

$\chi^{2}=6.77, d f=2, p=<0.05$

Table 6: Relationship between HER-2/neu expression and tumour size ( $\mathrm{n}=50)$.

\begin{tabular}{cccccc}
\hline Tumour size & \multicolumn{2}{c}{ HER-2/neu+ve } & \multicolumn{2}{c}{ HER-2/neu-ve } & Total (\%) \\
& $\mathrm{n}$ & $\%$ & $\mathrm{n}$ & $\%$ & \\
\hline$<2 \mathrm{~cm}$ & 2 & $33.33 \%$ & 4 & $66.66 \%$ & $6(12 \%)$ \\
$2-5 \mathrm{~cm}$ & 11 & $36.67 \%$ & 19 & $63.33 \%$ & $30(60 \%)$ \\
$>5 \mathrm{~cm}$ & 2 & $14.29 \%$ & 12 & $85.71 \%$ & $14(28 \%)$ \\
Total & 15 & $30 \%$ & 35 & $70 \%$ & $50(100 \%)$ \\
\hline
\end{tabular}

$\chi^{2}=2.313, d f=2, p=>0.05$

Tumour $<2 \mathrm{~cm}$ in diameter \& tumour 2-5 $\mathrm{cm}$ showed more number of HER-2/neu positivity than that of tumour $>5 \mathrm{~cm}$ in diameter. But this correlation between the expression of HER-2/neu and tumour size was not statistically significant $(\mathrm{p}=>0.05)$

Table 7 Relationship between HER-2/neu expression and lymph node status (n=50).

\begin{tabular}{cccccc}
\hline & \multicolumn{2}{c}{ HER-2 + ve } & \multicolumn{2}{c}{ HER-2 -ve } \\
Lymph node status & $\mathrm{n}$ & $\%$ & $\mathrm{n}$ & $\%$ & Total (\%) \\
\hline Node positive & 12 & $34.29 \%$ & 23 & $65.71 \%$ & $35(70 \%)$ \\
Node negative & 2 & $28.57 \%$ & 5 & $71.43 \%$ & $7(14 \%)$ \\
Not assessed & 1 & $12.50 \%$ & 7 & $87.50 \%$ & $8(16 \%)$ \\
Total & 15 & $30 \%$ & 35 & $70 \%$ & $50(100 \%)$ \\
\hline
\end{tabular}

In this table the relationship between HER-2/neu expression and lymph node status was not statistically significant $(p=>0.05)$

\section{Discussion}

This cross-sectional study was performed to see the correlation HER-2/neu expression with age, tumour size, grade, differentiation and lymph node deposit in invasive breast carcinoma. A total 50 cases of invasive breast carcinoma were included in this study. In this study, age distribution ranged from 22 to 64 years with a mean \pm SD of age
$42.64 \pm 10.26$ years. In this study carcinoma was graded into well differentiated (grade 1), moderately differentiated (grade 2), and poorly differentiated (grade 3).Well differentiated tumour was 20(40\%), moderately differentiated tumour was $18(36 \%)$ cases and poorly differentiated tumour was $12(24 \%)$. Ayadi et $\mathrm{al}^{2}$ described in his study that grade 1 tumour was $11 \%$, grade 2 was 
$63.2 \%$ and grade 3 tumour was $25.8 \%$. Taucher et $\mathrm{al}^{3}$ mentioned grade $118 \%$, grade 2 was $32.3 \%$ grade 3 was $40.5 \%$ and grade $39.2 \%$. Huang et $\mathrm{al}^{4}$ showed Grade $1-260.8 \%$ and grade 3 was $39.2 \%$. Vang et $\mathrm{al}^{5}$ mentioned grade $126.2 \%$, grade 2 $30.8 \%$ and grade 3 was $43.0 \%$. So the result of this study is consistent with most of the previous studies.

Almasri \& Hamad ${ }^{6}$ and Farzamiet $\mathrm{al}^{7}$ found that younger age groups ( $\leq 50$ years age) are more likely to have HER-2/neu over expression than patients older than 50 years. Ratnatunga \& Liyanapathirana $^{8}$ also found HER-2/neu overexpression more among the younger $(\leq 45$ years) group than the older ( $>45$ years) group. Taucheret $\mathrm{al}^{3}$ described age group of $<35$ years and $>35$ years. All of them found significant correlation $(p<0.05)$ between HER-2/neu over expression and patient's age. But Ayadi et $\mathrm{al}^{2}$ did not find significant correlation between HER2/neu over expression and patient's age (women older or younger than 50 years). In the present study younger age group ( $\leq 45$ years) showed 42.31\% over expression of HER-2/neu and older age group ( $>45$ years) showed $16.67 \%$ HER$2 /$ neu over expression which is statistically significant $(p=<0.05)$.

In this study $30 \%$ cases are HER-2/neu positive and $70 \%$ are HER-2/neu negative when considering $3+$ score as positive and score $0,1+$, $2+$ as negative. Arafah ${ }^{9} 35.3 \%$, Hossain ${ }^{10} 32 \%$, Slamon et al ${ }^{11} 28 \%$, Benohr et al $^{12} 26.6 \%$, Jacobs et $\mathrm{al}^{13} 24 \%$, Almasri \& Hamad ${ }^{6} 24 \%$ cases found HER-2/neu positive which correlated well with this study. But Taucheret $\mathrm{al}^{3}$, Ayadi et $\mathrm{al}^{2}$, Huang et $\mathrm{al}^{4}$, Vang et $\mathrm{al}^{5}$, Prati et $\mathrm{al}^{14}$ found HER-2/neu over expression in $17.3 \%, 18.1 \%, 10.9 \%, 13.0 \%$, $19.1 \%$ cases respectively. So it was found that HER-2/neu positivity ranges from $13.0 \%$ to $35.3 \%$.

In this study, tumour size ranged from 1 to $8 \mathrm{~cm}$ with a mean \pm SD of size $4.39 \pm 1.564 \mathrm{~cm}$. The median size was $4.45 \mathrm{~cm}$. Among those less than 2 $\mathrm{cm}$ tumour was $6(12 \%)$ cases, $2-5 \mathrm{~cm}$ tumour was $30(60 \%)$ cases and more than $5 \mathrm{~cm}$ tumour was 14(28\%) cases. Huang et $\mathrm{al}^{4}$ described tumour size less than $2 \mathrm{~cm}$ was $52.90 \%$ and more than 2 $\mathrm{cm}$ tumour was $47.10 \%$, Ayadi et $\mathrm{al}^{2}$ described tumour size $<5 \mathrm{~cm}$ was $76 \%$ and $>5 \mathrm{~cm}$ was $23.9 \%$. So in this study tumour size is more than previous study. This may be due to late service seeking approach in our country due to different causes such as poor health knowledge, economic status, social ignorance and deprivation, no national programme to generate knowledge, poor Electronic media/ TV/paper work. Tumours of $<2$ $\mathrm{cm}$ size are $33.33 \%$, 2-5 cm tumours are $36.67 \%$ and tumours of $>5 \mathrm{~cm}$ size are $14.29 \%$ HER-2/neu positive. The correlation between tumour size and HER-2/neu positive are not statistically significant $(p=>0.05)$. Huang et $\mathrm{al}^{4}$, Ayadi et $\mathrm{al}^{2}$ and Farzamiet $\mathrm{al}^{7}$ (2009) also found no significant association between tumour size and HER-2/neu reactivity. Huang et $\mathrm{al}^{4}$ showed that tumour size $<20 \mathrm{~mm}$ were $10 \%$ HER-2 positive and tumours $>20 \mathrm{~mm}$ were $11.4 \%$ positive $(\mathrm{p}=0.617)$, Ayadi et $\mathrm{al}^{2}$ and Farzamiet $\mathrm{al}^{7}$ found $\mathrm{p}=0.104$ and $\mathrm{p}=0.497$ that is no significant correlation. But Taucher et $\mathrm{al}^{3}$ found inversely associated relationship between tumour size and HER-2/neu status with $p=0.0076$. Almasri \& $\operatorname{Hamad}^{6}$ described in their study that tumours with strong HER-2 expression tended to be larger than those lacking expression with mean size of $4.7 \mathrm{~cm}$ and $4 \mathrm{~cm}$ respectively.Among tumour size more than $5 \mathrm{~cm}, 35 \%$ were HER-2 positive and tumour of 2$5 \mathrm{~cm}$ size was $22 \%$ positive .

Among the 20 well differentiated tumours 3(15\%) showed positive reactivity and $17(85 \%)$ tumours showed negative reactivity for HER-2/neu. In case of moderately differentiated tumours $5(27.78 \%)$ cases showed positive reactivity, 13(72.22\%) tumours showed negative reactivity HER-2/neu. Among 12 cases of poorly differentiated tumours 7(58.33\%) cases showed positive reactivity and and 5(41.67\%) tumours showed negative reactivity for HER-2/neu. The association between HER2/neu expression and tumour differentiation was statistically significant $\left(p=<0.05\right.$ ). Taucher et $\mathrm{al}^{3}$, Huang et $\mathrm{al}^{4}$ also found positive association between HER-2/neu expression and poor tumour differentiation which was statistically significant and Ayadi et $\mathrm{al}^{2}$ found marginal significance 
between HER-2 overexpression and histologic grade; only $14.8 \%$ of grade $1-2$ carcinoma were overexpressed compared to $27.5 \%$ with grade 3 carcinoma $(p=0.072)$. Arafah ${ }^{9}$ and Hossain ${ }^{10}$ did not find significant association between tumour differentiation and HER-2/neu reactivity that is $\mathrm{p}$ value $>0.25$ and $\mathrm{p}=0.504$ respectively.

In this study among 35 patients of lymph node metastasis 12 (34.29\%) showed positive reactivity and 23 (65.71\%) showed negative reactivity for HER-2/neu. Of 7 patients with no lymph node metastasis $2(28.57 \%)$ showed positive reactivity and 5(71.43\%) showed negative reactivity for HER-2/neu. The relationship between HER-2/neu expression and lymph node status was not statistically significant $(p=>0.05)$. Similar findings were also reported by other authors as Taucher et $\mathrm{al}^{3}$ in their study among 923 patients 441 had lymph node metastasis and among them 81(18.4\%) had HER-2/neu positive tumours and patients without lymph node metastasis $(n=482)$ $78(16 \%)$ had HER-2/neu positive tumours. No significant correlation between lymph node status and HER-2/neu status was found $(\mathrm{p}=0.38)$. Prati et $\mathrm{al}^{14}$ among 73 cases with positive lymph node found that $16(21.92 \%)$ cases were HER-2 positive and 57(78.08\%) were HER-2 negative. Among 80 lymph node negative cases, $12(15 \%)$ were HER-2 positive and 68(85\%) were HER-2 negative. There was no significant correlation between lymph node metastasis and HER-2 status. Huang et $\mathrm{al}^{4}$ in his study found that among lymph node positive cases $12.1 \%$ were HER-2 positive and among lymph node negative cases $10 \%$ were HER-2 positive which was not statistically significant $(\mathrm{p}=0.692)$. But Borg et $\mathrm{al}^{15}$ found statistically significant relationship between HER-2 amplification and the number of positive nodes $(\mathrm{p}=0.044)$ and Ayadi et $\mathrm{al}^{2}$ found strong association between HER-2/neu expression and lymph node involvement $(\mathrm{p}=0.000)$.

\section{Conclusion}

Analysis of HER-2/neu status in breast cancer is important because it provide valuable prognostic, predictive and therapeutic information. In this study HER-2/neu overexpression was evaluated by immunohistochemistry in 50 patients with infiltrating breast carcinomas and was positive in 15 cases (30\%). In this study it was revealed that HER-2/neu expression significantly correlates with high histological grade and age of the patient.

\section{References}

1. Mettlin C. Global breast cancer mortality statistics. CA Cancer J Clin 1999; 49: 138-44.

2. Ayadi L., Khabir A, Amouri H, Karray S, Dammak A, Guermazi M. Correlation of HER-2 overexpression with clinico-pathological parameters in Tunisian breast carcinoma. World Journal of Surgical Oncology 2008; 6: 112-119

3. Taucher S, Rudas M, Mader RM, Gnant M, Dubsky $P$, Bachleitner $T$ et al. Do We Need HER2/neuTesting for All Patients with Primary Breast Carcinoma? Cancer 2003; 98: 2547-53.

4. Huang $\mathrm{HJ}$, Neven $P$, Drijkoningen $M$, Paridaens $R$, Wildiers $\mathrm{H}$, Limbergen $\mathrm{EV}$ et al. Association between tumour characteristics and HER-2/neu by immunohistochemistry in 1362 women with primary operable breast cancer. J ClinPathol 2005; 58: 611-616

5. Vang R, Cooley LD, Harrison WR, Reese T, Abrams J. Immunohistochemical Determination of HER-2/neu Expression in Invasive Breast Carcinoma. Am J Clin Pathol 2000; 113: 669-674.

6. Almasri NM, Hamad MA. Immunohistochemical evaluation of human epidermal growth factor receptor 2 and estrogen and progesterone receptor in breast carcinoma in Jordan. Cancer Research, 2005; 7: 598-604.

7. Farzami MR, Anjarani $\mathrm{S}$, Safadel $\mathrm{N}$, Amini $\mathrm{R}$, Moghaddam MG, Roosta B et al. Association between the expression of hormone receptor , HER-2/neu over expression and tumour characteristics in women with primary breast cancer. Internet scientific publications, The Internet Journal of Pathology, 2009; 8: 2

8. Ratnatunga N, Liyanapathirana LVC. Hormone receptor expression and Her-2/neu amplification in breast carcinoma in a cohort of Sri Lankans. Ceylon Medical Journal 2007; 52(4):133-136.

9. Arafah M. Correlation of Hormone Receptors with Her 2/neu Protein Expression and the Histological Grade in Invasive Breast Cancers in a Cohort of Saudi Arabia. Turkish Journal of Pathology 2010; 26(3): 209-215

10. Hossain S. Study on estrogen receptor, progesterone receptor and HER-2/neu expression pattern by immunohistochemistry in 87 cases of 
invasive breast cancer. MD Thesis, 2011. Department of Pathology, BSMMU.

11. Slamon DJ, Clark GM, Wong SG, Levin WJ, Ullrich A, McGuire WL. 'Human breast cancer: Correlation of Relapse and Survival with Amplification of the HER-2/neu Oncogene. Science 1987; 235:177-182.

12. Benohr P, Henkel V, Speer R, Vogel U, Soltar K, Aydeniz B. HER-2/neu expression in breast cancerA comparison of different diagnostic methods. Anticancer Research 2005; 25:1895-1900.

13. Jacobs TW, Gown AM, Yaziji H, Barnes MJ, Schnitt SJ. HER-2/neu Protein Expression in Breast
Cancer Evaluated by Immunohistochemistry. A Study of Interlaboratory Agreement. American Journal of Clinical Pathology 2000; 113: 251-258.

14. Prati $\mathrm{R}$, Apple SK, Jianbo H, Gornbein JA, Chang HR, Histopathologic Characteristics Predicting HER-2/neuAmplification in Breast Cancer. The Breast Journal 2005; 11( 6):433- 439.

15. Borg A, Tandon AK, Sigurdsson H, Clark GM, Ferno M, Suzanne A. HER-2/neuAmplification Predicts Poor Survival in Node-positive Breast Cancer. Cancer Res 1990; 50:4332-4337.

All correspondence to Dr. Sharmin Ferdousi Assistant Professor, Department of Pathology Rajshahi Medical College, Rajshahi. Email: sharminferdousiruma@gmail.com 